\title{
KESANTUNAN BERBAHASA \\ PADA TRANSAKSI ONLINE SHOP \\ ALYA HIJAB BY NAJA
}

\author{
JAMILATUS SA'ADAH ${ }^{1}$, AIDA AZIZAH ${ }^{2}$, OKTARINA PUSPITA WARDANI ${ }^{3}$ \\ Prodi PBSI, FKIP, Universitas Islam Sultan Agung \\ rissa.saadah626@gmail.com¹, aidaazizah@unissula.ac.id²,oktarinapw@unissula.ac.id³
}

\begin{abstract}
Abstrak
Kesantunan berbahasa merupakan tatanan kesopanan berbahasa yang harus dimiliki manusia. Berbahasa yang santun akan memberikan efek baik bagi pemakainya. Efek baik dari kesantunan berbahasa digunakan para penjual dan pembeli salah satunya di online shop Alya Hjab by Naja pada saat melakukan transaksi. Penjual dan pembeli ketika melakukan transaksi jual beli di online shop Alya Hjab by Naja menggunakan bahasa yang santun sehingga kesepakatan keduannya berjalan dengan lancar. Berkaitan dengan hal tersebut permasalahan pada penelitian ini yaitu tentang terjadinya pematuhan kesantunan berbahasa pada transakasi online shop Alya Hijab by Naja. Tujuan dari penelitian ini untuk menambah pengetahuan tentang penelitian kesantunan berbahasa pada transaksi online shop Alya Hijab by Naja bagi pembaca dan mampu memberikan pandangan bagi masyarakat yang berkaitan dengan kesantunan dalam transaksi jual beli pada media online shop agar masyarakat selektif dalam melakukan transaksi online shop. Selain itu, juga dapat memberikan kontribusi bagi penjual online shop dalam memahami pematuhan dalam transaksi jual beli online shop. Metode penelitian yang digunakan yaitu metode kualitatif yang bertujuan untuk mendeskipsikan dan menganalisis sebuah gambaran pada fenomena pristiwa di masyarakat. Data dalam analisis peneliti yaitu kata, kalimat, frasa, dan wacana. Sumber data yang digunakan peneliti yaitu berupa tuturan dialog transaksi penjual dan pembeli di online shop Alya Hijab by Naja pada bulan Agustus-Desember 2017. Hasil analisis bahwa terjadinya pematuhan kesantunan berbahasa terdapat maksim kearifan, maksim kedermawanan, maksim pujian, maksim kerendahan hati, maksim kesepakatan, dan maksim simpati.
\end{abstract}

Kata kunci: kesantunan berbahasa, transaksi, online shop

\begin{abstract}
Language courtesy is an order of language decency that must be possessed by human beings. A polite language will give good effect to the wearer. Good effects of language politeness used by sellers and buyers one of them in Alya Hijab by Naja at the time of the transaction. Seller and buyers when making a sale and purchase online shop Alya Hijab by Naja using polite language so that both agreements run smoothly. Realated to this problem in occurrence of compliance in the language of online transaction shop Alya Hijab by Naja. The purpose of this research is to add knowledge about the research of language politeness in online transaction shop Alya Hijab by Naja for reader and
\end{abstract}


able to give view for society related to politeness in buying and selling transaction shop online. In understanding the compliance in the transaction buying and selling online shop. The research method used is a qualitative method that aims to describe and analyze a picture on the phenomanon of events in society. Data in the analysis of researchers that is words, sentences, phrases, and discourse. Tha data source used by the researcher is in the from of speech transaction dialogue of seller and buyer in online shop of Alya Hijab by Naja in Augusts-December 2017. From the analysis that the occurrence of compliance in language there is maxim of wisdom, maxim of generosity, maxim of praise, maxim of humility, maxim agreement, and maxim of sympathy.

Keywords: language politeness, transaction, online shop

\section{PENDAHULUAN}

Bahasa digunakan sebagai sarana komunikasi manusia satu dengan lain. Bahasa digunakan untuk berintraksi secara tersirat maupun tersurat. Bahasa memiliki fungsi untuk menyampaikan pesan dari pembicara ke pendengar. Fungsi dari bahasa tersebut terdapat sebuah ide dan informasi.

Tuturan suatu bahasa pada transaksi jual beli di masyarakat terlihat santun saat dipakai penutur. Kesantunan berbahasa dapat terlihat santun jika ada aturan kesantunan berbahasa yang terdapat enam maksim, yakni maksim kearifan, maksim kedermawanan, maksim pujian, maksim kerendahan hati, maksim kesepakatan, dan maksim simpati yang diungkapkan oleh Leech (dalam Oka, 2015:206207) . Pranowo (dalam Chaer, 2010:62) menyatakan "Kesantunan berbahasa merupakan tuturan yang menghasilkan tuturan kesetujuan bersama." Kesetujuan bersama dalam berkomunikasi yang menggunakan kesantunan berahasa ketika digunakan penutur dan petutur.

Dalam Alquran surah Thaha:

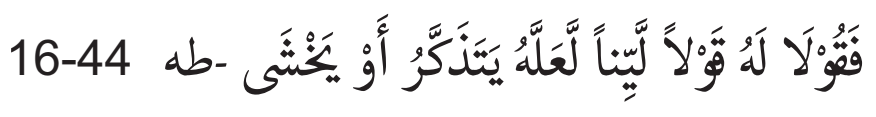

Artinya: "Maka berbicaralah kamu berdua kepadanya dengan kata-kata yang lemah lembut, mudahmudahan dia sadar atau takut". Sebuah ujaran maupun tulisan yang berbentuk komunikasi dikatakan santun sangat tergantung pada ukuran kesantunan masyarakat penutur bahasa yang dipakai. Maka kesantunan berbahasa sangat perlu dikaji guna mengetahui banyak kesantunan berbahasa pada manusia pada saat berkomunikasi.

Jual beli lewat daring di era globalisasi saat ini sangat populer di kalangan masyarakat karena banyak dinilai kepraktisannya. Selain itu, memiliki kelebihan saat berbelanja tidak membutuhkan tenaga hanya membuka aplikasi yang sudah tersedia di Gawai. Contohnya jual beli daring di Alya Hijab by Naja yaitu jual beli daring yang menjual suatu produk jilbab yang mengedepakan kualitas bahan dan jahitan dengan pelayanan yang baik. Belanja di gawai Online Shop Alya Hijab by Naja menggunakan aturan dalam berbahasa pada saat transaksi. Kegiatan transaksi jual beli daring pada Online Shop Alya Hijab by Naja dalam proses tawar menawar, mudah dipahami oleh penjual dengan pembeli karena menggunakan kesantunan berbahasa. Ngadiman (2008:58) menyatakan kepuasan konsumen dari aspek pelayanan dan kualitas barang atau jasa yang dibeli. Kepuasan konsumen terjalin ketika dalam kegitan transaksi menggunakan kesatuanan berbahasa. 
Berdasarkan pematuhan kesantunan berbahasa saat berkomunikasi jual beli daring, penelitian mengkaji pematuhan kesantunan berbahasa pada transaksi online shop Alya Hijab by Naja.

\section{METODE PENELITIAN}

Metode penelitian yang digunakan adalah penelitian kualitatif. Metode untuk mendeskipsikan dan menganalisis suatu gejala pristiwa dalam masyarakat (Sukmadinata 2015:60). Metode kualitatif digunakan untuk menemukan kalimat yang terdapat kesantunan berbahasa di analisis dengan enam maksim kesantunan berbahasa menurut Leech. Dalam penelitian ini digunakan pendekatan deskriptif kualitatif yang menghasilkan analisis data yang berupa gambaran lengkap di masyarakat.

\section{Data dan Sumber Data}

Data dalam analisis penelitian yaitu kata, kalimat, frasa, dan wacana. Sumber data yang digunakan peneliti yaitu berupa tuturan dialog transaksi penjual dan pembeli di online shop Alya Hijab by Naja pada bulan Agustus-Desember 2017.

\section{Teknik Pengumpulan Data}

Teknik pengumpulan data dalam penelitian ini adalah teknik yang mudah didapatkan atau disebut teknik fleksibel. Teknik fleksibel merupakan pelaksanaan secara keseluruhan dari data terdahulu sampai sekarang yang diperoleh (Sukmadinata 2016:114). Teknik fleksibel meliputi perencanaa, memulai pengumpulan data, dan pengumpulan data penutup.

\section{Instrumen}

Instrumen penelitian yang digunakan dalam penelitian ini human instrument yaitu penelitian sendiri. Segenap penguasaan teori dan wawasan peneliti terhadap bidang yang diteliti (Sugiyono 2017:222). Alat penting dalam penelitian ini adalah Instrumen kartu data.

Tabel 1. Kartu Data Penelitian

\begin{tabular}{|l|l|l|l|}
\hline NO & KODE & TUTURAN & KETERANGAN \\
\hline \multirow{2}{*}{} & & & Jenis Maksim : \\
\cline { 3 - 4 } & & & Kontek : \\
\cline { 3 - 4 } & & & Analisis : \\
\hline
\end{tabular}

\section{Desain Penelitian}

Langkah-langkah mengumpul data kesantunan berbahasa pada dialog transaksi penjul dan pembeli di online shop di Alya Hijab by Naja dalam penelitian ini yaitu (1) memilih sumber data dialog transaksi online shop Alya Hijab by Naja pada bulan Agustus-Desember 2017 di kumpulkan dalam bentuk screenshot chat, (2) membaca wacana transaksi online shop Alya Hijab by Naja pada bulan Agustus-Desember 2017, (3) memilih data transaksi online shop Alya Hijab by Naja pada bulan Agustus-Desember 2017 yang di petakan dalam enam maksim kesantunan berbahasa menurut teori Leech, dan (4) mencatat ke dalam kartu data. 


\section{Teknik Analisis Data}

Teknik analisis data yang digunakan dalam menganalisa tuturan yang tertulis pada transaksi online shop di Alya Hijab by Naja pada bulan Agustus-Desember 2017 ialah teknik analisis deskriptif kualitatif. Teknik analisis kualitatif deskriptif digunakan untuk mengurai permasalahan yang menjadi topik dalam penelitian ini sehingga hasil pembahasan lebih terperinci. Adapun langkah-langkah teknik analisis data yaitu 1) Memilih chat transaksi online shop di Alya Hijab by Naja pada bulan AgustusDesember 2017 yang berada di Whatsapp menentukan enam maksim kesantunan teori Leech, 2) Menganalisis memilih chat transaksi online shop di Alya Hijab by Naja pada bulan Agustus-Desember 2017 yang sudah di kelompokan di dalam kartu data.

\section{PEMBAHASAN}

Penelitian ini terdapat pematuhan kesantunan berbahasa pada kegiatan transaksi Online Shop Alya Hijab by Naja pada bulan Agustus-Desember 2017.

Jenis Maksim yang Mematuhi Kesantunan Berbahasa pada Kegiatan Transaksi Online Shop Alya Hijab by Naja pada Bulan Agustus-Desember 2017

Berdasarkan hasil analisis data yang diperoleh jenis maksim yang mematuhi berbahasa pada kegiatan transaksi online shop Alya Hijab by Naja bulan Agustus-Desember 2017 yaitu maksim kearifan, maksim kedermawanan, maksim kerendahan hati, maksim pujian, maksim pemufakatan, dan maksim simpati. Hasil analisis kesantunan berbahasa yang mematuhi berbahasa pada kegiatan transaksi online shop Alya Hijab by Naja bulan Agustus-Desember 2017 dapat dilihat pada Tabel 2 berikut ini.

Berikut uraian pembahasan jenis maksim yang mematuhi kesantunan berbahasa pada kegiatan transaksi Online Shop Alya Hijab by Naja berikut ini.

\section{1). Maksim Kearifan}

Tuturan yang memiliki prinsip dasar untuk selalu mengurangi keuntungan pada diri sendiri.

\section{Bentuk Tuturan :}

Penjual : "Wa'alaikumsalam kak. Untuk rawisnya harga reseller 20.000/pc beli 4 gratis 1 ya kak. Mari kak diorder".

Konteks : Pada tuturan penjual menunjukan bahwa pelayanan penjual menguntungkan pembeli. Kalimat yang bercetak miring, menunjukan kedermawanan penjual dengan cara menyaranakan kepada pembeli untuk membeli 4 pcs jilbab rawis, gratis 1 pc jilbab plain rawis.

Dituturkan penjual dalam pengajuan ajakan untuk membeli jilbab rawis dengan ilokusi komisif yang menguntungkan bagi pembeli. Tuturan penjual menguntungkan pembeli dengan memberikan saran kepada pembeli untuk membeli 4pcs jilbab plain rawis, gratis 1pc jilbab plain rawis. Hal itu tidak menyiratkan kerugian penjual. Kalimat menguntungkan dalam wacana tulis menurut Leech akan lebih baik. Karena tuturan yang memaksimalkan keutungan orang lain itu terlihat arif. Seperti tuturan penjual dengan memberikan sebuah ajakan untuk order jilbab plain rawis dengan harga reseller yang 
lebih murah dibandingkan dengan harga normal. Cara itu dengan tidak langsung menduga pembeli sudah menjadi reseller resmi.

\section{Bentuk Tuturan :}

Pembeli : "Assalamualaikum maaf mau tanya pasmina catton embosnya ready warna apa aja ya".

Penjual : "Waalaikumsalam kakak untuk customer baru pulau jawa bisa langsung chat di nomor ini yah kak $+62812 X X X X X X$ dan untuk customer luar jawa bisa order lewat WA sini ya kak 087700656XXXXXX dan BBM: D12XXXXX. Terima kasih".

Konteks : Pembeli menanyakan warna jilbab pasmina catton embos yang tersedia. Penjual memberikan saran untuk memesan pesanan sesuai alamat pembeli.

Dialog pada tuturan pembeli, menanyakan warna yang tersedia jilbab pasmina catton embos. Penjual dengan umpan tuturan saran yang menguntungkan bagi pembeli yang tidak merugikan penjual. Hal itu dengan cara memberi informasi kepada pembeli untuk memesan pesanan sesuai alamatnya, dengan melihat media sosial Alya Hijab pada nomor yang sudah tertera. Keuntungan tersebut untuk memudahkan pemesanan dan memepercepat pada pelayanan bagi pembeli.

\section{Bentuk Tuturan :}

Pembeli : “Ilusin dapat potongan gak ne, Fancy bergo masih ready juga kan. Mau sekalian 1 lusin say”.

Penjual : "Untuk harga sudah net kakak :-). Untuk produk saula size S Alhamdulillah kak masih ada beberapa stok readynya kakak. kalau kakak berkenaan mau jadi reseller resmi kami bisa dapat harga khusus reseller resmi kami kak, namun ada syaratnya kak".

Konteks : Pembeli dengan tuturan akan membeli jilbab bergo satu lusin jika dapat potongan harga. Penjual dengan tuturanya menyarankan pembeli untuk menjadi reseller resmi Alya agar dapat potongan harga.

Pengajuan permintaan pada tuturan dialog tersebut, pembeli meminta potongan harga pada pembelian 1 lusin jilbab bergo saula. Tuturan penjual dengan menjawab dengan ilokusi komisif yang menguntungkan bagi pembeli. Hal itu tidak menyiratkan kerugian penjual, kecuali dengan memberikan saran kepada pembeli untuk daftar menjadi reseller resmi Alya Hijab yang nantinya dapat potongan harga setiap pembelian produk dari Alya Hijab.

\section{Bentuk Tuturan :}

Pembeli : "Berapa harganya?”.

Penjual : "Sutra Versace Scraf harga normal 159.900 dan ini lagi ada promo diskon 25\% jadi harganya 119.900".

Konteks : Pembeli menanyakan dengan tuturan harga jilabab Sutra Versace Scraf harganya secara normal. Penjual denan tuturan memberikan informasi jilbab Sutra Versace Scraf sedang 
ada promo diskon $25 \%$.

Pertanyaan tuturan dialog yang dituturkan pembeli, harga jilbab Sutra Versace Scraf. Umpanan pertanyaan tuturan penjual dengan ilokusi komisif yang menguntungkan pembeli. Namun tidak menyiratkan kerugian penjual kecuali, memberi saran kepada pembeli ikut promo Sutra Versace Scraf diskon $25 \%$ lebih murah dari harga normal.

\section{2). Maksim Kedermawanan}

Tuturan yang membuat keuntungan diri sendiri sekecil mungkin; buatlah kerugian diri sendiri sebesar mungkin.

\section{Bentuk Tuturan :}

Pembeli : "Dress hanifa warna biru elektrik ada".

Penjual : "Belum ada kak. Adanya seperti digambar kak $\odot$;, bagaimana kak. Mungkin warna denim kak. Hampir sama kok kak, electrick blue namun agak gelap".

Konteks : Pembeli dengan tuturan ingin membeli dress hanifa warna biru elektrik namun, warna tersebut belum ada. Penjual dengan tuturan memberikan saran kepada pembeli, bahwa warna biru elektrik mirip dengan warna denim.

Pada tuturan dialog tersebut pembeli memberikan tuturan bahwa, ketersediaan dress hanifa warna biru tua. Tuturan umpanan penjual bahwa dress hanifa warna biru elektrik belum ada. Hal itu penjual dengan tuturan tetap memberikan tindakan ilokusi komisif dengan memberikan ajakan untuk menganti pilihan warna yang hampir mirip dengan warna biru tua yaitu warna denim.

\section{Bentuk Tuturan :}

Pembeli : "Kalau bisa minta tolong jangan sampai lewat bulan januari ini ya kak, soalnya saya mau keluar kota".

Penjual : "Siap kak. kami usahakan semaksimal kami ya kak. InsyaAllah sebelum bulan februari kami kirim ya kak $:-$. Mohon kesediannya untuk menunggu ya kak :)”.

Konteks : Pembeli dengan tuturan meminta ke penjual agar pesanannya dikirim sebelum bulan Januari. Penjual memberikan umpan tuturan dengan cara memberi keuntungan pembeli. Hal itu dengan cara memaksimalkan pengerjaan pesanan pembeli.

Pada dialog tersebut, pembeli dengan tuturan meminta ke penjual agar pesanannya dikirim sebelum bulan Januari. Tuturan umpanan penjual yang mengandung tuturan Ilokusi komisif, menguntungkan bagi pembeli. kuntungan tersebut dilakukan dengan cara memaksimalkan pengerjaan pesanan pembeli.

\section{Bentuk Tuturan :}

Pembeli : "Kak yang X 093 kubusnya ganti light yellow gpp".

Penjual : "Oke kak, kami ganti ya kak. Terima kasih (;)". 
Konteks : Pembeli dengan tuturan meminta jilbab warna kubus ganti warna yellow. Penjual memberikan umpan tuturan dengan cara kesiapan mengganti pesanan kubus menjadi warna yellow.

Permintaan tuturan pembeli dengan tuturan kompetitif yang mengurangi ketidakharmonisan pada dialog tersebut. Tuturan pembeli untuk meminta ganti pesananya jilbab warna kubusnya ganti light yellow. Hal itu merugikan penjual. Namun, penjual memberikan tuturan umpanan dengan berusaha memaksimalkan keuntungan pembeli dengan cara mengunakan tindakan menyenangkan bagi pembeli, membolehkan ganti warna.

\section{Bentuk Tuturan :}

Pembeli : "Kubus di F 422 diganti emerald. Dusty pinknya ganti pink ya. kak, peachnya masih ada?"

Penjual : “Oke kak. Peach ada Kak".

Konteks : Tuturan pembeli untuk meminta ganti pesananya jilbab warna kubus ganti light yellow. Penjual dengan tuturan memberikan tindakan kesiapan untuk menggantinya.

Bagian pengajuan pada dialog tersebut pembeli mengunakan ilokusi kompetitif yang mengurangi ketidakharmonisan. Tuturan yang tersirat pada kalimat pembeli untuk meminta ganti warna pesananya yang merugikan penjual. Penjual memberikan umpanan tuturan pembeli dengan berusaha memaksimalkan keuntungan pembeli, dengan cara menambahkan beban penjual. Cara itu mengunakan tindakan menyenangkan dengan membolehkan ganti warna. Meski mengurangi keuntungan penjual dengan menambah bebannya.

\section{Bentuk Tuturan :}

Pembeli : “Ading ada tambhan orderan, sebelum kak transfer. Zahra ukuran S warna: Hitam, Milo, white yang pakai pet semua".

Penjual : "REKAPAN PESANAN

Kode $=$ NA 050

Detail Pesanan $=$ Saula M $4 \times 55.000=220.000$ Saula L 65.000

Zahra S pet $3 \times 50.000=150.000$ total $=5$ PcS

Berat $=2 \mathrm{~kg}$, Ongkir $=92.000$, ekspedisi $=J N E$ Oke

TOTAL TRANSFER= 526.950".

Konteks : Pengajuan yang dituturkan pembeli ingin tambah pesanan sebelum direkap pesanannya. Penjual berusaha memaksimalkan keuntungan pembeli dengan menotalkan ulang 
pesanannya pembeli.

Pengajuan yang dituturkan pembeli ingin tambah pesanan sebelum direkap pesanannya. Tuturan penjual berusaha memaksimalkan keuntungan pembeli dengan tindakan komisif yaitu dengan cara menambahkan beban bagi penjual menotalkan ulang pesanannya pembeli.

\section{Bentuk Tuturan :}

Pembeli : "Sis apa orderanku blm dkrm?"

Penjual : "Admin cek dulu yah Kak."

Pembeli : "Oke Sis."

Penjual : "Pesanan Kakak Alhamdulillah sudah kami kirimkan tanggal 23 Februari Kak, Mohon ditunggu yah Kak $\odot$;. “

Konteks : Pembeli menanyakan pesanannya sudah dikirim apa belum. Penjual dengan cara mengecekan pesanannya di bagian pecking.

Tuturan pada dialog tersebut pembeli menanyakan pesanannya sudah dikirim apa belum. Penjual berusaha memaksimalkan keuntungan tindakan ilokusi komisif bagi pembeli, dengan cara menambahkan beban bagi penjual. Hal itu dilakukan dengan cara mengecekkan pesananya pembeli dibagian pecking.

\section{3.) Maksim Pujian}

Tuturan yang banyak memuji orang lain. maksim pujian juga disebut maksim rayuan.

\section{Bentuk Tuturan :}

Pembeli : "Nyaman banget bahanya jilbab saulanya dimuka jatuhnya bagus tidak menyesal beli sampai 3 biji."

Penjual : "Alhamdulillah Kakak jika paketannya sudah sampai, semoga Kakak suka dan puas dengan produk Alya Hijab ya Kak (:). Jangan lupa tag foto cantik di IG Alya ya Kak, siapa tahu bisa menang photo Contest nya Kak. semoga Kak Rini dilancarkan rezekinya dan sehat selalu ya Kak. Terima kasih sudah order di Alya Hijab Kak, Alya tunggu orderan selanjutnya ya Kak @:."

Konteks : Tuturan pembeli yang bercetak miring menyenangkan penjual dengan menyatakan pujian.

Tuturan pembeli dengan memberikan pujian kepada penjual bahwa pesanan yang dipesan bahannya nyaman saat dipakai karena bahannya sesuai yang diharapkan. Pembeli tidak menyesal membeli jilbab produk dari Alya meski itu berjumlah banyak. Meski penjual dapat tuturan pujian, penjual memberikan tuturan balik kepada pembeli untuk memesan kembali produk dari Alya. 


\section{Bentuk Tuturan :}

Pembeli : "Hijabnya enak kak di pakai tidak licin suka banget $\odot$;."

Penjual : "Masya Allah cantiknya Kakak @- Alhamdulillah ya Kak, jika kakak suka dengan produk Alya. Semoga Kakak sekeluarga dilancarkan rezekinya ya Kak. Terima kasih sudah order di Alya Hijab Kak :-."

Konteks : Tuturan pembeli memuji penjual, ketika jilbabnya sudah sampai. Tuturan pujian tersebut terdapat pada kalimat bercetak miring yang dituturkan pembeli.

Dialog pada tuturan penjual dan pembeli pada konteks tersebut, pembeli dengan memberikan tuturan pujian kepada penjual. Hijab yang dipesan pembeli enaka dipakai, tidak licin, dan merasa selalu suka. Sehingga memberikan tindakan ilokusi menyenangkan memuji bagi penjual. Hal itu tidak ada kerugian bagi penjual dan pembeli.

\section{Bentuk Tuturan :}

Pembeli : "Say makasih ya paket umama screfnya udah sampe bahanya lembut bgt..oh iya paket bergo lengannya juga udh sampe kemaren."

Penjual : "Alhamdulliah Kakak, ditunggu orderan berikutnya yah Kak (:) Jangan lupa teg foto di IG kami yah kak $\odot$;".

Konteks : Pembeli mengabarkan bahwa pesanannya sudah datang dan memberikan pujian bagi penjual. Penjual membalas pujian dengan doa untuk pembeli.

Dialog pada tuturan penjual dan pembeli, pembeli memberikan pujian yang menguntungkan penjual. Jilbab umama scref bahanya lembut. Sehingga pembeli memberikan tindakan ilokusi yang menyenangkan bagi penjual. Maka hal itu tidak merugikan penjual dan pembeli.

\section{4.) Maksim Kerendahanhatian}

Tuturan yang memberikan pujian sedikit mungkin pada diri sendiri dan memberikan kecaman sebanyak mungkin pada diri sendiri.

\section{Bentuk Tuturan :}

Pembeli : "Iya Kak, pasti jadi langganan. Soalnya aku suka sama modelnya dipakai nyaman dan pas banget. Coba merk lain yang semodel begitu gak enak dipakainya semoga produksi berikutnya bisa dapat kain yang sebagus produksi pertama ya kak (-)".

Penjual : "Alhamdulillah Kakak. Terima kasih banyak ya Kak :-; insya Allah kami akan selalu berikan yang terbaik untuk customer baik dari sisi pelayanan maupun kualitasnya Kak (;)".

Konteks : Pembeli memuji jilbab yang dipesannya sudah sampai. Penjual menanggapi pujian dengan doa.

Dialog pada tuturan penjual dan pembeli, pembeli memberikan pujian yang menguntungkan 
penjual. Model jilbab produk dari Alya Hijab nyaman saat dipakai dan akan membeli lagi produk dari Alya, sehingga pembeli memberikan tindakan ilokusi yang menyenangkan bagi penjual. Penjual memberikan umpan tuturan dengan merendahkan hati dengan mengecilkan tuturanya dengan cara senang diberi masukan saran perbaikan dari pembeli.

\section{Bentuk Tuturan :}

Pembeli : "Iya Kak, kainnya masih tergolong bagus kok kalau dibandingin merk lain, tapi kalau saya lebih suka sama produksi aisyah yang pertama yang cuma 3 warna dulu itu tebelnya pas. Sukses terus buat Alya Hijabnya :-).”

Penjual : "Iya terima kasih atas kepercayaanya ya Kak (:) dan mohon maaf sebelumnya ya Kak (:). Amin ya Allah, sukses juga buat Kakak $;$.). InsyaAllah kami akan lebih selektif lagi untuk pemilihan bahan Kak dan tetap terjaga kualitasnya. Terima kasih atas pengertiannya ya Kak $\odot$."”

Konteks : Tuturan pada dialog pembeli dan penjual tersebut, penjual dengan tuturanya tetap merendahkan hati. Ketika dapat pujianjilbab aisyah kainnya tergolong bagus dibandingkan merk lain.

Pada tuturan dialog tersebut, ketika penjual dapat pujian dari pembeli. Jilbab aisyah kainnya tergolong bagus dibandingkan merk lain. Penjual menanggapi tuturan pembeli dengan tuturan mengecilkan kalimat tuturannya, kemurahan hati diri sendiri yang normal, dan konvensional tidak dibesar-besarkan. Hal itu meski ada kritikan dari pembeli penjual tetap menanggapi dengan tuturan rendah hati.

\section{Bentuk Tuturan :}

Pembeli : "Suka banget jadi pengen semua warna hehehe".

Penjual : "Alhamdulillah ya kak jika kakak suka dengan produk alya... Semoga kakak sekeluarga dilancarkan rezekinya dan sehat selalu ya kak $\odot$. Terima kasih sudah order di AlyaHijab kak, Alya tunggu orderan selanjutnya ya kak (-)"

Konteks : Pembeli dengan memberikan tuturan pujian, bahwa pembeli merasa suka dengan warna jilbab yang dibeli dari Alya. Penjual memberikan umpan tuturan sebuah doa untuk pembeli.

Dialog pada tuturan penjual dan pembali, ketika penjual dapat pujian dari pembeli. pembeli dengan tuturan ingin memiliki koleksi semua warna jilbab produk Alya. Tuturan pada dialog tersebut, penjual dengan memberikan tanggapan ilokusi komisif pada tuturan pembeli. Hal itu dengan merendahkan hati, mendoakan pembeli.

\section{Bentuk Tuturan :}

Pembeli : "Hijabnya sudah saya pakai, Nyaman dipakainya (-)". 
Penjual : "Jangan lupa tag foto cantiknya di IG Alya ya Kak. siapa tahu bisa menang photo contestnya Kak".

Konteks : Tuturan pembeli mengunakan maksim pujian. Tuturan tersebut mengabarkan penjual dengan pujian kalau jilbanya yang dibeli terasa nyaman pada saat dipakai. Hal itu dituturakan pada tuturan dialog pembeli yang bercetak miring.

Dialog pada tuturan penjual dan pembeli tersebut, pembeli merasa puas dengan jilbab yang dibelinya, dan memberikan pujian bagi penjual. Jilbab yang dibelinya nyaman saat di pakai. Penjual dengan memberikan umpan kerendahan hati dengan tindakan ilokusi komisif yang menguntungkan pembeli. Keuntungan tersebut menyarankan pembeli untuk ikut lomba foto cantik dengan memakai produk dari Alya Hijab.

\section{Bentuk Tuturan :}

Pembeli : "Kak, barangnya sudah aku terima. Terima kasih banyak ya, warnanya cantik banget".

Penjual : "Alhamdulillah kakak jika paketannya sudah sampai, Semoga kakak suka dan puas dengan produk Alya Hijab ya kak :- Jangan lupa tag foto cantik di IG Alya ya kak, siapa tahu bisa menang photo Contest nya kak. semoga kak Indah dilancarkan rezeki nya dan sehat selalu ya kak, Terima kasih sudah order di Alya Hijab kak, Alya tunggu orderan selanjutnya ya kak $\odot$ ").

Konteks : Pembeli mengungkapkan kalau jilbab yang dipesananya sesuai harapan, dengan memberikan pujian kalau jilbab yang dibeli warnanya cantik kepada penjual.

Ketika tuturan penjual mendapatkan pujian dari pembeli tuturan pujian bahwa jilbab yang dipesan warnanya cantik. Tuturan pembeli menyenangkan penjual karena adanya kesepakatan yang menghasilkan kepuasan pembeli dan penjual. Penjual dengan memberikan umpan kerendahan hati dengan tindakan ilokusi komisif yang menguntungkan pembeli. Keuntungan tersebut dengan mendoakan dan menyarankan pembeli untuk ikut lomba foto cantik dengan memakai produk dari Alya Hijab.

\section{5.) Maksim Kesepakatan}

Tuturan yang cenderung melebih-lebihkan kesepakatannya dengan orang lain dan juga mengurangi ketidaksepakatanya dengan ungkapan-ungkapan penyesalan, kesepakatan sebagaian, dan sebagainya.

\section{Bentuk Tuturan :}

Pembeli : "Iya sist nanti kalau sudah langsung kabarin aja ya sisi”.

Penjual : "Siap kakak nanti admin informasikan. No resinya 15555XXXXXX via pos kilat. itu kak no resinya".

Konteks : Pembeli dengan tuturan jika nomor resi sudah datang, penjual segera menghubungi penjual. Penjual mengiyakan pernyataan pembeli. 
Persetujuan pada tuturan dialog penjual dan pembeli tersebut tampak adanya kecocokan persepsi antara penjual dan pembeli. Jika nomor resi sudah datang, maka penjual segera menghubungi pembeli. Penjual mengiyakan pernyataan pembeli. Hal itu dengan komisif bagi pembeli dan penjual yang saling menguntungkan.

\section{Bentuk Tuturan :}

Pembeli : "Say jilbab sauranya ready warna apa aja?".

Penjual : “Jilbab saula ya kak maksudnya. Saula polos/S ready warna: Red, Lime, Tosca, Maroon, purple, elektrik blue, lavender".

Konteks : Pembeli bertanya jilbab warna jilbab saula yang tersedia. Penjual menjawab dengan tuturan, jilbab saula tersedia.

Konteks pada dialog tersebut, pembeli dengan tuturan pertanyaan apa saja warna yang tersedia pada jilbab saula. Penjual memberi umpan tuturan dengan komisif bahwa jilbab saula ukuran $\mathrm{S}$ tersedia banyak warna. Kecocokan dialog pada transaksi penjual dan pembeli tersebut memberikan efek kepada pembeli untuk membeli produk jilbab saula.

\section{Bentuk Tuturan :}

Pembeli : "Ongkirnya Naik ya?? Hehehe".

Penjual : "Iya kak, dari pihak pos ada kenaikan ongkirnya kakak".

Pembeli : “Oke kak, terima kasih ya”.

Penjual : "Siap kakak terima kasih kembali kakak (:)".

Konteks : Pembeli menanyakan kenaikan ongkir. Penjual menjawab, ongkir via pos ada kenaikan pembayaran.

Penjual dan pembeli pada tuturan dialog tersebut ada kegiatan tawar menawar harga ongkir. Tuturan tersebut tampak adanya kecocokan persepsi antara Penjual dan pembeli. Bahwa ongkir pengiriman naik. Penjual mengiyakan pernyataan pembeli dengan komisif, kalau ongkir pengiriman ekspedisi pos naik.

\section{Bentuk Tuturan :}

Pembeli : "Kalau bisa 3 kg pas. Esok ditransfer."

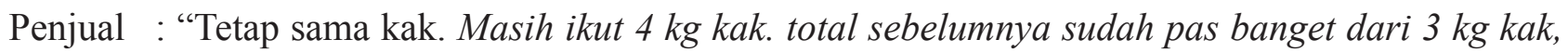
tambah $1 \mathrm{~kg}$ lagi ya kak, biar $4 \mathrm{~kg}$ hehehe, nanti tambah orderan menjadi 5 pcs kak. kami tunggu kabar baiknya ya kak laila."

Pembeli : "Ya sudah kalau gitu minta totalkan semua aja ya, biar aja 4 kg (:)."

Konteks : Tuturan pembeli ingin memastikan berat pesanannya, setelah mengetahui beratnya menyepakati pesananya segera akan di transfer. 
Pada tuturan dialog penjual dan pembeli tersebut terlihat adanya tawar menawar dan tampak adanya kecocokan persepsi antara penjual dan pembeli berupa tambah pesanan 5 pcs berat orderan 4 kg. Penjual mengiyakan pernyataan pembeli dengan menotalkan orderanya dengan berat $4 \mathrm{~kg}$.

\section{Bentuk Tuturan :}

Pembeli : "Pesanan (produk, warna, size): rawis black 2, navy 2. total seluruh pesanan= (4pcs) gratisnya rawis white ya kak".

Penjual : "Baik kak, namun sebelumnya Alya kabarkan jika transfer harus hari ini ya kak. Karena, jika besok sudah tidak dapat bonus lagi kak. Alya totalkan dulu pesanannya ya kak".

Pembeli : "Siap, transfer kemana info ya. Saya transfer sekarang".

Konteks : Tuturan pembeli ingin order jilbab promo rawis putih. Penjual memberi peringatan promo akan berakhir, pembeli menyepakati segera melakukan transfer.

Pada tuturan dialog tersebut antara penjual dan pembeli tampak adanya kecocokan persepsi. Penjual memberikan penjelasan kepada pembeli. Ketika promo waktunya sudah selesai, transfer pembayaran segara di lakukan karena tidak melakukan pembayaran hari itu juga tidak mendapatkan bonus jilbab. Pembeli memberikan umpan tuturan dengan mengiyakan pernyatan penjual, transfer pembayaran akan segera di bayar. Hal itu adanya kesepakatan bersama untuk mencapai keuntungan penjual dan pembeli.

\section{Bentuk Tuturan :}

Pembeli : "Saya pesan yang grey dan red aja mbak, berapa totalnya mbak, yang pakai pet ya mbak". Penjual : "siap kakak, untuk yang pakai pet harus ikut PO ya kakak”.

Pembeli : “Oke Mbak”.

Penjual : "Rekapan pesanan Kode $=$ MU 018

Detail pesanan $=1$. Zahra pet $2 \times 65.000=130.000$ total $=2 \mathrm{pcs}$

$$
\text { Berat }=1 \mathrm{~kg} \text { Ongkir }=35.000 \text { ekspedisi }=\text { Pos kilat }
$$

Total Transfer $=165.018$ Berikut rekening kami $=-$ Mandiri ac.035XXXXXXX -BCA ac. $135 X X X X X$-Permata ac. $331 X X X X X X "$.

Konteks : Pembeli memesan jilbab pakai pet dan menanyakan totalanya. Penjual mengabarkan pesanan ikut PO kepada pembeli. Pembeli menyepakati ikut PO dan penjual menotalkan pesananya.

Pembeli dengan tuturan pengajuan permintaan kepada penjual. Pembeli ingin pesanannya segera ditotalkan. Penjual pada tuturanya tampak adanya kecocokan persepsi pembeli. Penjual 
mengiyakan menotalkan pesanan jilbab grey dan red. Cara itu menggunakan tindakan komisif yang menguntungkan pembeli dan penjual.

\section{Bentuk Tuturan :}

Pembeli : “Udah ya Mbak”. (gambar bukti pembayaran transfer)

Penjual : "Baika kak segera Alya proses pesananya ya kak. Terima kasih - .). Kode pesanan PN 099 total 3 pcs, Faiza S pet, pink, brokrn white, black".

Konteks : Pembeli melakukan transfer pembayaran jilbab yang dibelinya. Penjual menyepakati, jilbab pembeli segera di proses dan dikirim ke alamat pembeli.

Pada tuturan dialog tersebut, penjual dan pembeli tampak ada adanya kecocokan persepsi yang terjalin adanya kesepakatan. Tuturan pembeli dengan mengabarkan kalau sudah melakukan transfer pembayaran yang sudah disepakati bersama. Penjual dengan tuturan mengiyakan pernyataan pembeli. Hal itu dengan ilokusi komisif, bahwa transfer pembayaran pembeli sudah masuk, kemudian pesanan akan segera diproses dengan kode pesanan PN 099 total total 3 pcs, Faiza S pet, pink, brown white, black.

\section{6.) Maksim Simpati}

Tuturan yang menerangkan ucapan selamat dan ucapan berlangsung kawa.

\section{Bentuk Tuturan :}

Pembeli : “Assalamualaikum kak maaf nih Kak, gimana mau transfer ya ATM akaunya ilang, akunya kerja. Insya Allah hari Senin aku transfernya ya".

Penjual : "Wa'alaikumsalam kak, semoga dapat penggantinya ya kak. siap kak, tidak ap-apa kak (;)".

Konteks : Pembeli belum sempat transfer karena, lagi audit. Penjual memberikan pengertian masih bisa melakukan transfer.

Pada tuturan dialog penjual dan pembeli tersebut, penjual memberikan tuturan simpatinya kepada pembeli. Ketika ATM pembeli hilang, penjual dengan ucapan simpatinya dengan rasa sedih. Hal itu dengan ucapan doa tampak ada rasa simpati belasungkawan kepada pembeli. Hal itu dengan tuturan yang menguntungkan dengan memberikan keringanan ke pembeli atas suatu kehilangan.

\section{Bentuk Tuturan :}

Pembeli : "Kak maaf saya belum transfer, barusan lahiran soalnya. tapi masih ada ya barangnya. besok insya Allah saya transfer ya".

Penjual : "Baik kak gpp, Alya tunggu kabar baiknya segera ya kak (-)".

Pembeli : "Iya kak kalau gk besok ya besok lusa ya, masih di RS soalnya (-)".

Penjual : Iya kak, gpp kok kak $;$, Selamat ya kak, semoga anaknya menjadi anak yang sholeh 
solehah kak @)".

Konteks : Pembeli belum sempat transfer, Penjual memberikan keringanan waktu.

Pembeli dengan tuturan penawaran kepada penjual. Pembeli ketika belum sempat melakukan transfer pembayaran karena melahirkan. Tuturan penjual dengan tuturan simpatinya yang menyenangkan, dengan mengucapkan selamat atas kelahirannya. Pembeli memberikan umpan tuturan akan segera melakukan transfer pembayaran pesanannya.

\section{Bentuk Tuturan :}

Pembeli : "Ig an. SuciXXXXX".

Penjual : "Selamatyakak, sudah menjadipemenang spam like dan comment, kakak akan mendapatkan giveaway dari Alya. Barangkali mau order sekalian mungkin kak (;), ongkir Alya yang tanggung”.

Konteks : Pembeli mengabarkan namanya tercantum menang dalam acara di instagram. Penjual memberikan rasa simpati.

Dialog yang dituturan penjual kepada pembeli ketika pembeli menang spam like dan comment di Instagram. Penjual dengan tuturan simpatinya yang menyenangkan bagi pembeli. Hal itu dengan memberikan selamat kepada pembeli atas pemenangan spam like dan comment di Instagram.

\section{PENUTUP}

Simpulan dari hasil analisis data kesantunan berbahasa pada transaksi online shop Alya Hijab by Naja bulan Agustus sampai Desember 2017, terdapat 85 tuturan pematuhan kesantunan berbahasa yang meliputi enam maksim menurut Leech, yaitu maksim kearifan, maksim kedermawanan, maksim pujian, maksim kerendahan hati, maksim kesepakatan, dan maksim simpati.

\section{DAFTAR PUSTAKA}

Leech, Geoffrey. 1983. Prinsip-Prinsip Pragmatik. Cetakan ke-1. Terjemahan M.D.D. Oka. Jakarta: Universitas Indonesia Press.

Sugiyono. 2017. Metode Penelitian Kuantitatif, Kualitatif, dan R\&D. Bandung: Alfabeta.

Sukmadinata, Nana Syaodih. 2016. Metode Penelitian Pendidikan. Bandung: PT Remaja Rosdakarya.

Ngadiman. 2008. Marketing untuk SMK Jilid 1. Jakarta: Direktorat Pembinaan Sekolah Menengah Kejuruan. 
Nugroho, Adi.2006. e-Commerce Memahami Perdagangan Moderen di Dunia Maya. Bandung: Informatika.

Kenrianto, Iwan. 2017. Bisnis Online Revolution. Jakarta: PT Gramedia Pustaka Utama.

Anam, Atfalul. 2011. "Kesantunan Berbahasa dalam Buku Ajar Bahasa Indonesia Tataran Unggul: untuk SMK dan MAK Kelas XII Karangan Yustinah dan Ahmad Iskak". Skripsi. Yogyakarta: Universitas Negeri Yogyakarta. http://eprints.uny.ac.id/1197/ (diunduh 19 April 2017) 